\title{
DiÁlogos E APROXIMAÇões
}

PIRES, Maria Fátima Novaes; SANTANA, Napoliana Pereira; e SANTOS, Paulo Henrique Duque (orgs.). Bahia: escravidão, pós-abolição e comunidades quilombolas - estudos interdisciplinares. Salvador: EDUFBA, 2018. 276p.

Organizar uma coletânea com vários/ as autores/as não é tarefa fácil no meio acadêmico. Exigirá, no mínimo, lidar com os diferentes tempos de produção dos textos, leitura dos originais, às vezes sugerir cortes, acréscimos, revisões para enquadrá-los nos padrões acadêmicos e no limite de páginas estabelecido. Juntas as partes para compor o todo, é a vez da burocracia editorial. Passada a fase de produção é a hora de lançar a obra. Organizadores/as e autores/as esperam boa recepção das suas contribuições, especialmente entre os pares, ávidos por encontrar no novo livro informações valiosas para suas pesquisas e novas interpretações sobre temas já discutidos.

Certamente, esse caminho foi percorrido nesta coletânea. Lançada no segundo semestre de 2018, ela é resultado das discussões realizadas na VII Semana da Consciência Negra e IV Seminário das Comunidades Quilombolas no Território Velho Chico, ocorrido em 2016 na cidade baiana de Bom Jesus da Lapa.

O livro conta com onze capítulos e está dividido em quatro partes: “Escravidão e Pós-Abolição”; "Cultura afro-brasileira e territorialidade”; “África e patrimônio”; e uma "Resenha”. Comento aqui os dez textos que compõem as três primeiras partes. Deixo de fora a última por destoar dos propósitos da coletânea. ${ }^{1}$

1 A resenha em questão tem o título Fotografia: o cristal do tempo como fonte para a história e é de autoria de Rafael Magalhães, Bento Chastinet, Jamile Palofaz, Valney Mascarenhas Filho, 
Com a contribuição de gente de diversas áreas do saber, o livro busca ser interdisciplinar. Com uma ressalva, que citarei mais adiante, os textos abordam (ou permitem refletir sobre) questões políticas, culturais e sociais, além de métodos e fontes relacionados às experiências afro-brasileiras, concentrando-se em temas como escravidão, cultura e identidade quilombolas. O recorte espacial privilegiado é a Bahia, mas há textos que fogem a esse marco. As discussões vão do século XVIII ao XXI.

A primeira parte é composta por textos que englobam temas sobre escravidão e pós-abolição em três espaços diferentes: Alto Sertão, Recôncavo baiano e sudeste brasileiro. Seguindo uma ordem cronológica, coube a Gabriela Amorim Nogueira Silva abrir a coletânea com o capítulo "Escravos que viviam por si: sobrevivências, autonomias e hierarquias no 'Certam de Sima do Sam Francisco' (século XVIII)”. A autora usa livros de batismo, casamento e óbito para analisar as experiências de escravos

Paulo Sérgio Souza e Rafael de Jesus Oliveira. A obra resenhada é de M. E. L. Borges, História e fotografia, $2^{\mathrm{a}}$ ed, Belo Horizonte: Autêntica, 2005. nas fazendas de proprietários absenteístas, especialmente as da família Guedes de Brito, a famosa Casa da Ponte, localizada na freguesia de Santo Antônio de Urubu de Cima, margem direita do rio São Francisco. Sua tese é de que a ausência dos senhores possibilitou aos escravos, africanos e brasileiros, criar uma comunidade com maior autonomia e mobilidade. Alguns chegaram a administrar propriedades de senhores ausentes, estabelecendo uma hierarquia dentro do cativeiro.

Diversos fatores atuavam para diferenciar os escravos: cor, origem, família, tipo de relação com seus senhores, ocupação, para ficar nos mais conhecidos pela historiografia. Silva traz um elemento a mais: escravos senhores de escravos. Só recentemente historiadores/as têm dado maior atenção a essa questão. ${ }^{2}$

2 Sobre o tema, ver João José Reis, "De escravo a rico liberto: a trajetória do africano Manoel Joaquim Ricardo na Bahia oitocentista”, Revista de História, n. 174 (2016), pp. 15-68; e Daniele Santos de Souza, "Preto cativo nada é seu?": escravos senhores de escravos na Cidade da Bahia no século XVIII” in G. Raggi, J. Figuerôa-Rego e R. Stumpf (orgs.), Salvador da Bahia: interações entre América e África (séculos XVI a XIX) (Salvador: EDUFBA; Lisboa: CHAM, 2017), pp. 51-72. 
A autora destaca que a maioria dos escravos de escravos eram mulheres e relaciona essa prática a tradições de povos africanos que tinham a mulher como importante meio de produção e reprodução nas comunidades. Destacar a existência de escravos senhores de escravos pode servir de argumento para os que negam os horrores da escravidão, hoje tão em voga, e dos que se posicionam contra cotas e outras formas de reparação racial. Porém, penso que Silva e outros/as historiadores/as, ao tocar nesse ponto, apenas reforçam o quão perverso foi o sistema escravista e como ele estava arraigado na sociedade. ${ }^{3}$

Apesar da autora indicar conhecimento dos procedimentos de controle senhorial nas propriedades absenteístas, o texto carece de uma melhor discussão sobre o assunto. O leitor que ainda pensa o sertão como espaço isolado, mesmo com trabalhos mostrando o contrário, poderá concluir que viver por si era,

3 Diferentes estudos mostraram o quanto o escravismo estava disseminado na sociedade. Além dos artigos de Reis e Souza citados na nota anterior, ver o livro de Sidney Chalhoub, A força da escravidão: ilegalidade e costume no Brasil oitocentista, São Paulo: Companhia das Letras, 2012. para o escravizado, sinônimo de decidir sobre seu destino ou de que havia uma escravidão mais branda. ${ }^{4}$ A ausência do senhor não significava menor dominação, mas sim um processo de controle senhorial diferente, exercido à distância, através do olhar da sociedade na qual os escravos estavam inseridos e a partir do medo diante da ameaça ou do cometimento de punições, inerente ao sistema, como a perda da autonomia conquistada.

Os escravos urbanos e os dos engenhos baianos, exerciam diferentes ocupações assim como os das fazendas de gado. Mas, eram os vaqueiros os mais importantes dentro da estrutura social e produtiva daquelas unidades. Mesmo considerando sua importância, não é foco de Silva detalhar a vida dos escravos vaqueiros. Ao final do texto, ela afirma que o número de vaqueiros escravizados diminuiu no século XIX, assim como seu papel na administração de fazendas.

4 Um estudo que contesta o isolamento do sertão é o de Isnara Pereira Ivo, Homens de cominho: trânsitos culturais, comércio e cores nos sertões da América portuguesa, século XVIII, Vitória da Conquista: Edições UESB, 2012. 
Mas o leitor não fica sem saber um pouco mais sobre eles, pois o segundo capítulo da coletânea, "Participação escrava no 'sistema de sorte ou giz': a trajetória do vaqueiro Braz no sertão do São Francisco oitocentista”, de Napolitana Pereira Santana, trata justamente desses indivíduos, da sua maior autonomia e de suas estratégias na busca pela alforria. Usa para isso a trajetória do escravo vaqueiro Braz. O recorte espacial também é a freguesia de Santo Antônio do Urubu de Cima, mas no século XIX.

Não sendo seu objetivo, Santana acaba por reforçar a existência de hierarquias entre os escravos apontada por Silva. Eram os escravos vaqueiros os mais especializados, valorizados e aqueles que, dentro da estrutura produtiva, conseguiam alforria para si e suas famílias, através do pecúlio acumulado pelo "sistema de sorte ou giz”. Sorte ou Giz era como se denominava no sertão o sistema de pagamento aos vaqueiros, fossem eles escravos ou livres, nas fazendas de gado. Consistia em dividir uma porcentagem da produção (nascimento do gado vacum, equino, asinino ou muar) periodicamente entre os vaqueiros e os proprietários.
De forma apropriada, Santana sugere que a proporção e a periodicidade variavam e dependiam dos acordos entre os envolvidos e de práticas locais. Quanto mais animais o vaqueiro conseguisse conservar vivo, maior a sua recompensa. Os nascimentos, mortes, vendas, abates, matalotagens etc. eram registrados no Livro, Caderno ou Rol de chiqueiro, no Livro de rês e no Livro de gado. ${ }^{5}$

Os dois primeiros capítulos acabam por se complementar, funcionando muito bem na estrutura da coletânea, e demonstrando que, em alguns espaços, os escravos podiam ter maior prestígio, recursos e influência do que muitos homens livres que conviviam com eles, embora fossem juridicamente dependentes e propriedade de alguém.

Saindo das margens do São Francisco e passando para as margens do Paraguaçu, o texto de Clíssio Santos Santana, "Uma linha estreita: cor, escravidão e liberdade no Recôncavo baiano nas últimas décadas do XIX”,

5 Sobre assuntos discutidos neste parágrafo, conferir Lycurgo Santos Filho, Uma comunidade rural do Brasil antigo (aspectos da vida patriarcal no sertão da Bahia nos séculos XVIII e XIX), São Paulo: Companhia Editora Nacional, 1956. 
analisa como a cor era invocada em momentos de conflito para definir o lugar social e jurídico do indivíduo. O autor utiliza processos criminais de Cachoeira, importante município escravista baiano, mesmo no período de desmonte da escravidão. $\mathrm{O}$ texto é mais um contraponto à tese de Hebe Mattos de que o aumento do contingente de libertos e homens livres descendentes de escravos teria silenciado a cor da pele na documentação. ${ }^{6}$ O autor é contundente ao afirmar que "cor e origem poderiam ser acessadas em diversas circunstâncias do dia a dia”. Seus argumentos reforçam a mácula da escravidão para os libertos e possibilita pensarmos as razões da sociedade atual lançar mão da cor para demarcar o lugar social do indivíduo.

O quarto texto é de Maria de Fátima Novaes Pires. Em “A lente de Marc Ferrez e o trabalho escravo nas lavouras cafeeiras oitocentistas”, Pires apresenta as possibilidades do uso da fotografia para a análise da escravidão. Para ela, assim como outros documentos, a fotografia deve

6 Hebe Maria Mattos, Das cores do silêncio: os significados da liberdade no Sudeste escravista, Brasil Século XIX, Rio de Janeiro: Nova Fronteira, 1998. passar por uma crítica documental. As informações acessadas via fotografia também são passiveis de serem cruzadas com outras fontes. Pesquisadora com publicações sobre escravidão nos sertões baianos, dedicando-se ao uso de documentos cartoriais e judiciários, nesse texto ela sai um pouco da sua zona de conforto. Digo pouco por que os últimos parágrafos sugerem que seu interesse pela fotografia se deve ao tráfico interno interprovincial, foco de um dos seus mais importantes trabalhos sobre a escravidão e pós-abolição no Alto Sertão da Bahia. ${ }^{7}$

Coube a Paulo Henrique Duque Santos fechar essa primeira parte do livro. "Economia e sociedade na Primeira República. Caetité (18921930)" transita entre a História Social e a Econômica e mostra como os proprietários de Caetité se reinventaram após a abolição da escravidão, direcionando seus investimentos rurais para os imobiliários e o industrial. Como o livro trata de escravidão, pós-abolição e comunidades

7 Maria de Fátima Novaes Pires, Fios da vida: tráfico interprovincial e alforrias nos sertoins de sima - Ba (1860-1920), São Paulo: Annablume, 2009. 
quilombolas, era de se esperar que todos os textos dedicassem suas análises a assuntos direta ou indiretamente ligados a esses temas, mas não é isso que vemos no de Santos. Para não ser injusto, a escravidão aparece quando o autor compara seus dados, criados a partir de inventários, com os produzidos por Pires em Fios da vida, e apenas para dar suporte a sua tese central. Nesse sentido, o capítulo não dialoga com o conjunto da coletânea. Isso não tira suas qualidades, pois o autor aponta um importante caminho para realizar estudos sobre o sertão baiano na Primeira República, escapando de temas clássicos como coronelismo e cangaço, ainda hoje sinônimos, erroneamente, de violência e "incivilização". Santos apresenta moradores, especialmente os de posse, conectados com o contexto brasileiro e mundial, montando estratégias de inserção econômica e política na realidade pós-escravista.

A segunda parte da coletânea trata de heranças culturais, identidades e as lutas das comunidades negras rurais. Em “A cultura afro-brasileira no cotidiano e na arte barreirense", Gilson Brandão de Oliveira Júnior parte da ideia de que os estudos africanos podem ser usados para compreender as manifestações culturais afro-brasileiras. O autor procura demonstrá-lo através de breves análises de esculturas de Mestre Nêgo, artesão e fundador da Casa Branca de Oxalá, um dos mais antigos terreiros de umbanda da cidade de Barreiras, Bahia. As esculturas de Mestre Nêgo possuem, segundo Oliveira Júnior, características luso-afro-brasileiras.

Antes de chegar a essa conclusão, Oliveira Júnior faz um balanço conceitual a respeito de arte $\mathrm{e}$ artesanato (e por tabela, artista e artesão), mostrando como, a partir de parâmetros etnocêntricos e etnoestéticos, aquelas atividades foram paulatinamente se tornando opostas. O resultado é que arte hoje está relacionada a foros de alta cultura e veleidade intelectual, a qualidade superior, refinamento e erudição, enquanto artesanato é visto como algo rudimentar, primitivo, grosseiro e popular. Segundo a autor, aqui no Brasil esse processo teve início com a instalação das escolas de BelasArtes. Acrescenta que, mesmo tendo "negros que desafiassem a praxe e adentrassem nas academias", o processo serviu para afastá-los do 
que hoje denominamos arte e artista (p. 148). Outra questão tratada é a vinculação da produção artística e manual afro-brasileiras à religiosidade negra, principalmente aos terreiros de candomblé e à tradição oral, portanto, não acadêmica. Por fim, destaco a constatação do autor de que temos pouco conhecimento sobre as artes afro-brasileiras em razão da falta de documentos, especialmente da cultura material, e os registros escritos que nos chegaram foram produzidos por órgãos repressivos, por exemplo, objetos confiscados pela polícia em terreiros por ela invadidos.

O texto de Nivaldo Osvaldo Dutra, "Santos, sambas e rodas: manifestações culturais de comunidades negras de Mangal-Barro Vermelho, Bahia”, tem como foco as tradições e as identidades em duas comunidades negras rurais do médio São Francisco. Através da tradição oral e da observação de festejos (Folia de Reis, Roda São Gonçalo e festejos de São Sebastião), Dutra defende que essas comunidades buscam conciliar a preservação das tradições, defendidas pelos velhos, com as mudanças e atualizações levadas adiante pelos mais jovens. Seria justamente esse diálogo entre velhos e jovens o garantidor da permanência de uma tradição sempre renovada, em lugar de tratar essas comunidades como espaços imutáveis. A leitura remete a duas outras questões. A primeira são os múltiplos significados das festas em uma comunidade negra rural. Festejar é acessar tradições, reinventar, confraternizar, socializar e pertencer. O segundo ponto diz respeito às possibilidades metodológicas que se abrem para quem não se dedica à História Oral e nem pesquisa tempos mais recentes. De posse de informações sobre memória e ciente de que elas são constantemente (re)construídas, quem pesquisa a escravidão, por exemplo, poderá dialogar com o presente para tentar compreender aspectos culturais de comunidades negras formadas no XIX, ou mesmo de períodos mais recuados, como a da fazenda absenteísta dos Guedes de Brito, tratada por Gabriela Amorim Nogueira Silva na mesma coletânea. Aliás, muitas das atuais comunidades quilombolas foram formadas há cerca de dois séculos atrás.

O último texto dessa segunda parte é de Tiago Rodrigues Santos. Com formação acadêmica em duas 
áreas do conhecimento, Ciências Sociais e Geografia, e membro de projetos vinculados a estudos voltados para comunidades quilombolas e outras populações rurais, em seu trabalho, intitulado "Nem redistribuição, nem reconhecimento: a lógica da contestação à identidade e à territorialidade quilombola”, o autor discute as estratégias jurídicas usadas pelas elites para impedir o acesso de comunidades quilombolas à terra e aos recursos naturais. Sua tese é que as elites agrárias, e os poderes públicos que as representam, de forma "orquestrada e coesa”, escolheram negar a questão da identidade e da redistribuição de terras no combate contra as comunidades quilombolas. A estratégia teria se intensificado depois da Ação Direta de Inconstitucionalidade 3239/2004, movida pelo antigo Partido da Frente Liberal (PFL), atual Partido Democrata (DEM), contra o Decreto 4.887/2003, assinada pelo então presidente Luiz Inácio Lula da Silva, que adotou a autodefinição como um dos critérios fundamentais para o reconhecimento de comunidades quilombolas.

Tiago Rodrigues Santos elabora seus argumentos em torno de três casos ocorridos na Bahia que opuseram comunidades quilombolas a proprietários de terra: Rio das Rãs e Barra do Parateca, localizadas respectivamente em Bom Jesus da Lapa e Carinhanha, no sertão baiano; e Porto Dom João, em São Francisco do Conde, na região do Recôncavo da Bahia (neste caso o próprio executivo municipal se mobilizou contra a comunidade). De novembro de 2016, data do encontro que motivou a produção dessa coletânea, a outubro de 2020, quando redijo essa resenha, as estratégias de negação da identidade quilombola e a contestação do direito de acesso à terra das comunidades quilombolas (e também indígenas) ganharam uma dimensão ainda maior, tornando-se uma política de governo na atual gestão federal de extrema direita.

A terceira e última parte do livro tem como temas centrais África e patrimônio, e é composta por dois textos. O primeiro, "Encontro e desencontro Brasil-África: passado e presente - o caso de Angola”, de José Francisco dos Santos, é, como o próprio autor informa em nota, uma síntese de sua tese de doutorado e foi a fala de abertura do encontro gerador 
da coletânea. Talvez por isso ele seja mais informativo, sem grandes (nem pequenas) análises, buscando apresentar como se processaram as relações entre o Brasil e Angola, tomando como ponto de partida os momentos finais do século XIX. $O$ recorte temporal deixou de fora as relações durante o período do tráfico negreiro. O texto perde nesse aspecto, mas é uma opção metodológica do autor que, mesmo reconhecendo o peso e os horrores da escravidão, afirma não ser este o tema do trabalho.

O último capítulo, de Everaldo dos Santos Júnior e Fernanda Libório Ribeiro Simões, é o que considero, junto com o de Tiago Rodrigues Santos e de Clíssio Santos Santana (mesmo que este seja sobre o século XIX), os mais próximos de debates políticos atuais no Brasil e no mundo. Inserido no campo da Arqueologia e dos estudos sobre cultura material, em "O patrimônio como ação política e a arquitetura da diáspora africana”, os autores afirmam que a seleção de determinados materiais como patrimônio faz parte de um projeto de poder que busca homogeneizar a construção da identidade nacional. A partir dessa premissa, questionam o papel da Arqueologia nesse processo. O capítulo permite pensar a contribuição dos achados arqueológicos para a pesquisa sobre escravidão no Brasil na chave da cultura material, em confronto com o caráter hierárquico dos documentos escritos utilizados pelos historiadores, e sugere o diálogo entre Arqueologia e História.

Outropontomeparece relevanteno texto. Como deve ser de conhecimento de leitores e leitoras da Afro-Ásia, em 25 de maio de 2020, na cidade de Minneapolis, estado de Minnesota nos EUA, um policial branco assassinou o afro-americano George Floyd. Um ato brutal de racismo. Situação que os brasileiros conhecem bem, apesar de muitos preferirem não enxergar o obvio: o Brasil é uma sociedade altamente racista, que diariamente extermina moral, psicológica e fisicamente milhares de negros e negras. O assassinato de George Floyd foi o estopim para movimentos antirracistas em diversas partes do mundo, mesmo diante da ameaça invisível do coronavírus Sars-Cov-2, maximizada pelo também negacionismo e visões ideológicas de alguns governantes.

Entre as diversas manifestações antirracistas mundo afora, a derrubada 
e pichação de estátuas, monumentos ou locais ligados ao tráfico atlântico, à escravidão e a conquistadores foram as que mais chamaram a atenção da mídia. No Brasil, monumentos e nomes de logradouros públicos em homenagem a bandeirantes, traficantes e barões escravocratas também passaram a ser questionados. Entre historiadores/as e profissionais das ciências humanas o debate é intenso. Alguns são a favor da destruição dos monumentos, outros defendem que sejam transferidos das ruas e praças públicas para museus e há os que considerem mais adequados que fiquem onde estão por fazer parte da construção das camadas de memórias urbanas e que sejam ressignificados, ganhando novas informações que ajudem a sociedade a entender as misérias de seu passado. Quanto aos logradouros públicos, há quem reivindique que seus nomes sejam trocados por outros mais afins com um projeto de sociedade democrática, outros que novas ruas, avenidas e praças ganhem nomes de personalidades negras e indígenas, por exemplo.

Utilizando diferentes autores, Santos Júnior e Simões afirmam que o patrimônio oficial brasileiro, "muitas vezes, legitima práticas racistas e misóginas”, além de colonialistas. Escrevem:

Uma maneira incipiente de se entender as relações colonialistas do patrimônio nacional é observar a cidade do Salvador. Sabe-se que ela é considerada a cidade mais negra fora do continente africano. Porém, como uma rápida visita aos bens tombados é possível identificar uma cidade católica e colonial. Por que os bens materiais representativos de uma ancestralidade africana e indígena são pouco preservados e divulgados, se comparados proporcionalmente aos bens oriundos do período colonial? Justamente para tornar invisível um passado de diversas identidades e legitimar a construção de uma identidade coletiva com um passado homogêneo, em que somente as classes dominantes mereceram ações de preservação (p. 237).

Ressignificar, (re)construir memórias, (re)informar. Talvez seriam essas as propostas de Santos Júnior e Simões para o dilema que se coloca hoje sobre os patrimônios oficiais brasileiros. Em Salvador, cidade citada acima, pesquisadores/ as da UFBA e outras universidades baianas, como UNEB e UEFS, 
criaram o projeto Salvador Escravista, cujo foco central é debater esses pontos. ${ }^{8} \mathrm{O}$ debate não é novo, e está aí para subsidiar tomadas de posição mais claras dos que refletem sobre a questão. Eu sou um deles, apesar de pender para a defesa das ressignificações a partir de novas informações sobre os personagens homenageados.

Ressalvando as lacunas e o desequilíbrio quanto à profundidade entre os capítulos, a interdisciplinaridade da obra permite conhecer como determinados temas são tratados por diferentes áreas do conhecimento.
Isso é cada vez mais relevante e nos ajuda a pensar questões que o diálogo apenas interno a cada disciplina não permitiria. Um capítulo desconectado com o conjunto da coletânea, apesar de sua qualidade, e de uma resenha absolutamente fora de lugar, destoam no conjunto da obra. Destaco a variedade de temas, de espaços (apesar de maior concentração no Alto Sertão) e de abrangência temporal (quase três séculos), que permitem ampliar os caminhos metodológicos e teóricos dos autores.

\section{Jackson Ferreira (D)}

Universidade do Estado da Bahia

doi: 10.9771/aa.v0i62.42710

8 Para saber mais sobre a iniciativa, ver Salvador escravista $飞$. 